\title{
Clinical Vignettes
}

\section{Morbid Obesity: Obscuring the Diagnosis of Aortic Stenosis in a Patient with Cardiogenic Wheezing}

\author{
Eric D. Morrell, $M D^{7}$, William E. Katz, $M D^{2}$, and Asher A. Tulsky, $M D^{7,3}$ \\ 'Division of General Internal Medicine, Department of Medicine, University of Pittsburgh Medical Center, Pittsburgh, PA, USA; ${ }^{2} \mathrm{Heart}$ and \\ Vascular Institute, Department of Medicine, University of Pittsburgh Medical Center, Pittsburgh, PA, USA; ${ }^{3}$ Division of General Internal \\ Medicine, University of Pittsburgh Medical Center, Pittsburgh, PA, USA.
}

We report the case of a morbidly obese 65-year-old female who presented with repeated hypotensive episodes following dialysis. She was misdiagnosed as suffering from asthma, and eventually was found to have severe aortic stenosis. Obesity has become a common and formidable obstacle to gathering important diagnostic information in patients. Modern diagnostic lab tests and imaging modalities such as transthoracic echocardiography (TTE) can provide spurious data in the morbidly obese population, which can ultimately lead to misdiagnosis. In this clinical vignette, we discuss the relationship between the basic pathophysiologic mechanisms underlying aortic stenosis and patient clinical presentation. We also review the relevant literature and discuss the impact of obesity on the diagnosis of this condition.

KEY WORDS: obesity; aortic stenosis; diagnostic testing.

$\mathrm{J}$ Gen Intern Med 28(1):155-9

DOI: $10.1007 / \mathrm{s} 11606-012-2155-9$

(c) Society of General Internal Medicine 2012

\section{CASE}

A 65 -year-old morbidly obese (body mass index of 53.5) woman on chronic intermittent hemodialysis presented to the emergency department (ED) with worsening dyspnea and wheezing provoked by minimal exertion. Her associated symptoms included dry cough, but no chest pain or fever. Although she underwent dialysis two days prior to presentation without complication, over the preceding year she had multiple ED visits for lightheadedness and hypotension following dialysis sessions.

Past medical history was also notable for hypertension, type 2 diabetes, and obstructive sleep apnea (OSA). She had been bed-bound and living in an assisted living facility over the prior seven months after suffering from a fractured ankle. The patient reported a recent history of intermittent asthma treated with as-needed nebulized anti-cholinergic/

Received January 24, 2012

Revised June 16, 2012

Accepted June 19, 2012

Published online July 19, 2012 beta-agonists; however, she had never undergone formal pulmonary function testing. She had no history of tobacco use or abnormal environmental exposures. Ten days prior to presentation, the patient was admitted to the hospital with dyspnea and wheezing in addition to somnolence. On that admission, her $\mathrm{PaCO}_{2}$ was $72.9 \mathrm{mmHg}$, and brain natriuretic peptide (BNP) was $86 \mathrm{pg} / \mathrm{ml}$ (her baseline $\mathrm{PaCO}_{2}$ level had been in the mid-60s $\mathrm{mmHg}$, and she had no prior BNP levels drawn). She was treated for presumed asthma exacerbation with oral steroids and nebulizers and also started on nocturnal non-invasive positive pressure ventilation for untreated obesity hypoventilation and OSA. Following discharge, she reported no significant improvement in her symptoms. She was seen again in the ED four days prior to presentation with hypotension following dialysis and was treated successfully with a liter fluid bolus.

On arrival, the patient's temperature was $36.8{ }^{\circ} \mathrm{C}$, heart rate 68 beats/minute, blood pressure 120/74 $\mathrm{mmHg}$, respiratory rate $22 / \mathrm{min}$, and oxygen saturation $100 \%$ on room air. Physical exam was remarkable for an obese female in no acute distress and oriented $\times 3$, diffuse wheezing in all lung fields, and apparently normal $S_{1}$ and $S_{2}$ on cardiovascular examination with soft and extremely difficult to appreciate heart sounds. Volume status and jugular venous pressure were difficult to assess given her obesity and neck size. Admission laboratory data included a troponin that was $<0.10 \mathrm{ng} / \mathrm{mL}$, a white blood cell count of $9.3 \times 10^{9} / \mathrm{L}$ with a normal differential, arterial blood gas of $\mathrm{pH} 7.33$, $\mathrm{PaCO}_{2} 54 \mathrm{mmHg}$, and $\mathrm{PaO}_{2} 152 \mathrm{mmHg}$ on $2 \mathrm{~L}$ nasal cannula, and a creatinine level of $5.4 \mathrm{mg} / \mathrm{dl}$. EKG was consistent with normal sinus rhythm with a left bundle branch block that was unchanged from prior EKG's. Chest $\mathrm{x}$-ray quality was limited due to the patient's body habitus, but demonstrated normal heart size, clear lungs, and no acute processes. Peak expiratory flow measurements were $41 \%$ of predicted.

Based on the patient's wheezing, dyspnea, and peak expiratory flow measurements, ongoing asthma exacerbation was suspected. She was dialyzed on the night of admission with some mild improvement in her symptoms. Still, heart failure exacerbation was presumed to be less likely, as the patient had undergone three TTE over the 
preceding two years, all of which showed preserved left ventricular function. Although each study was noted to be "technically limited" due to the patient's size, the aortic valve mean gradient had never been measured to be $>$ $20 \mathrm{mmHg}$. TTE on this admission showed a calcified aortic valve (Fig. 1). Definity contrast was then ordered to augment the Doppler signal, and revealed an aortic valve peak velocity of $4.1 \mathrm{~m} / \mathrm{s}$ and a mean gradient of $39 \mathrm{mmHg}$ (Fig. 2). Heart catheterization confirmed the patient's severe aortic valve disease, and she was referred to cardiothoracic surgery for evaluation for aortic valve surgery.

\section{DISCUSSION}

This case illustrates the degree to which obesity has become one of the greatest barriers to successfully diagnosing patients in the current era. Although much has been written about the impact of obesity on disease management and treatment, surprisingly little attention has been paid to the role obesity plays in impairing the physician's ability to accurately and efficiently formulate a diagnosis. Given the degree to which obesity can impair a standard workup and evaluation, the proper diagnosis of aortic stenosis requires: 1) a thorough understanding of the disease course, and 2) an understanding of the limitations of standard diagnostic studies with an obese population.

Typically, aortic stenosis presents with dyspnea (heart failure), angina, or syncope. ${ }^{1}$ Although aortic stenosis has numerous etiologies, the end-state physiologic impairment that provokes these stereotypical symptoms is the same: impaired left ventricular outflow. In patients with aortic stenosis, the obstructive process is typically chronic and leads to gradual remodeling-usually manifested as con-

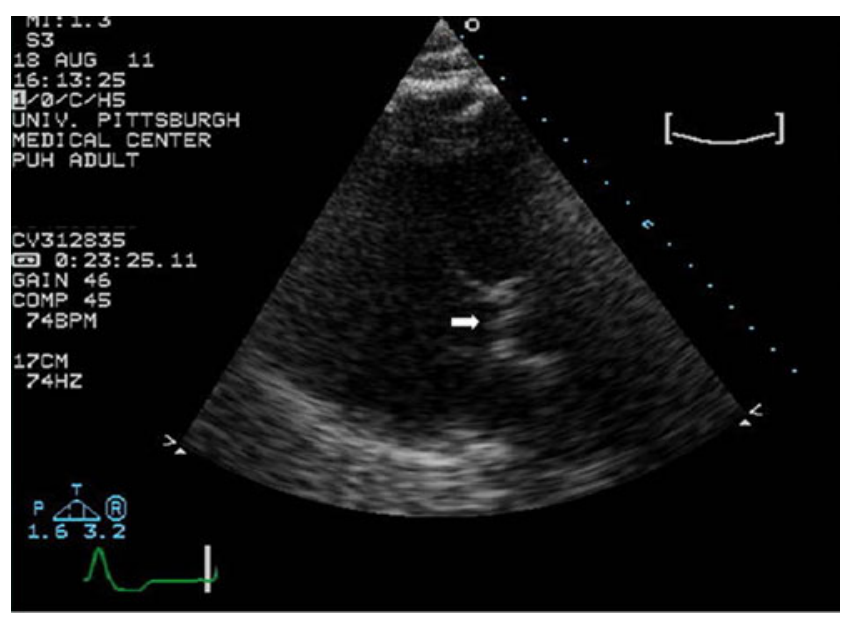

Figure 1. Parasternal long axis image that identified a heavily calcified aortic valve (arrow).

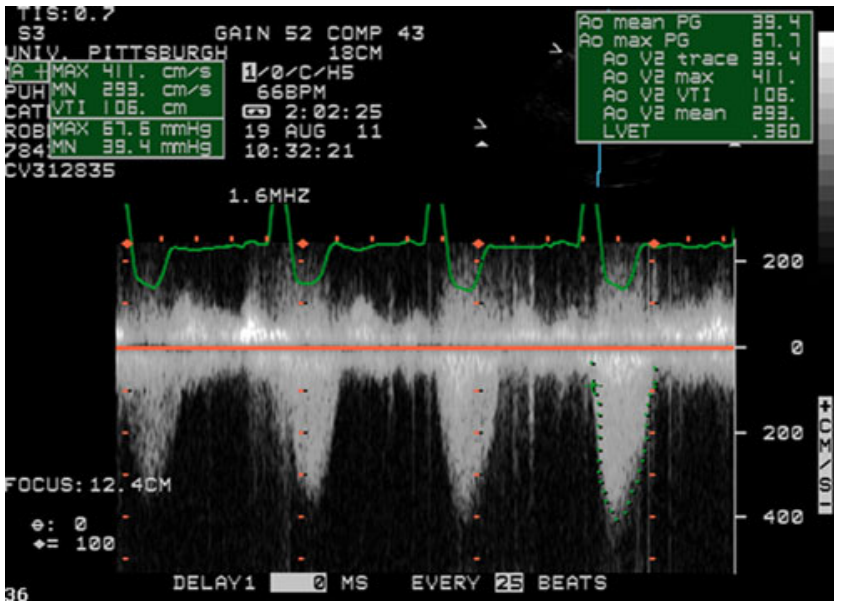

Figure 2. The continuous wave Doppler signal of the aortic valve velocity. The peak velocity, peak gradient, and mean gradient shown are consistent with severe aortic stenosis. The Doppler signal was only obtained with the aid of Definity contrast enhancement.

centric hypertrophy — of the left ventricle. Over time, this remodeling becomes deleterious and leads to impaired left ventricular relaxation that ultimately generates increased diastolic pressures. Additionally, as the degree of obstruction progresses, the systolic function of the heart cannot keep pace with the increasing aortic valve pressure gradient. This "two-hit" physiologic derangement - systolic and diastolic impairment - is what leads to the associated left heart failure and dyspnea. ${ }^{2}$

Impaired left ventricular outflow also leads to a relatively fixed cardiac output. As a result, patients with aortic stenosis are unable to compensate for any significant or abrupt reduction in preload and afterload. Indeed, prior to admission this patient had multiple ED visits for syncope, dizziness, and hypotension following her dialysis sessions. The inability of these patients to tolerate significant volume shifts is usually manifest during exertion. Patients with moderate to severe aortic stenosis are often encouraged to avoid vigorous exercise, as their fixed cardiac output is unable to compensate for exercise-triggered peripheral vasodilation. ${ }^{3}$ This physiologic phenomenon is also responsible for the cautious use of vasodilators and diuretics in aortic stenosis patients, as well as the anesthetist's difficulty in maintaining hemodynamic stability in these patients during surgery. ${ }^{4}$ Our patient's obesity and recent ankle fracture restricted her mobility, making it difficult to assess her functional capacity and symptoms. Her difficulty tolerating dialysis may have been the first clinical symptom suggesting that she was affected by severe aortic stenosis.

The characteristic exam findings of late peaking systolic crescendo-decrescendo murmur in the right upper sternal border, pulsus parvus et tardus (weak and delayed carotid pulse), and a soft or absent $\mathrm{S}_{2}$ were also obscured in this patient's physical exams. Cardiac auscultation has been 
shown to be a relatively sensitive and specific tool for identifying aortic stenosis when performed by an experienced cardiologist. ${ }^{5,6}$ Etchells and colleagues have demonstrated that the most reliable exam findings for identifying aortic stenosis are slow carotid artery upstroke (positive LR, 2.8-130), reduced carotid artery volume (positive LR, 1.03.2), maximal murmur intensity at the second right intercostal space (positive LR, 8.0-101), and reduced intensity of $\mathrm{S}_{2}$ (positive LR, 3.1-50). ${ }^{5,6}$ Yet, those physical exam findings were not appreciated in our patient despite the presence of severe disease. Recent data has shown that physical characteristics, especially body surface area, can have a significant impact on systolic murmur intensity in aortic stenosis. ${ }^{7}$ Nevertheless, the limitations of the physical exam in significantly obese patients are largely unknown. ${ }^{8}$

The presence of significant and diffuse expiratory wheezing in this case presented another confounding clinical finding. While the classic triad of wheezing, cough, and dyspnea is highly suggestive of asthma, the axiom "all that wheezes is not asthma," remains true., ${ }^{9,10}$ It has been shown that wheezing on exam correlates with the methacholine inhalation challenge only $43 \%$ of the time. ${ }^{11}$ Airway edema, bronchial hyper-responsiveness, and peribronchial cuffing are commonly associated with aortic stenosis and volume overload, ${ }^{12,13}$ and will often manifest as wheezing on exam. Indeed, up to one-third of patients older than age 65 with congestive heart failure present with cardiac asthma. ${ }^{14}$ While our patient did have a severely decreased peak expiratory flow rate and abnormal spirometry, her size prevented her from sitting up in bed and fully participating in the study. Pulmonary function tests are vital to diagnosing or excluding asthma, but they are dependent on patient effort and proper technique. ${ }^{15}$ In our patient's case, there was no question that her size and degree of dyspnea significantly interfered with her participation in the tests, limiting their value. That said, perhaps the greatest clue that our patient was suffering from cardiogenic wheezing as opposed to asthma was her previously poor response to appropriate asthma therapy. ${ }^{16}$

Distinguishing between cardiac and non-cardiac sources of dyspnea can be challenging; therefore, standard diagnostic studies such as BNP and TTE are often utilized to aid in the diagnosis. Unfortunately, as this case demonstrates, TTE and BNP have significant limitations in obese patients. TTE evaluation of aortic stenosis requires a high degree of technical acumen, and one of the most common causes of an underestimation of disease is an incorrect intercept angle between the ultrasound beam and the aortic valve outflow jet. $^{2,17}$ Assuming the intercept angle is within $15^{\circ}$ of parallel, the degree of underestimation of jet velocity is less than $5 \%{ }^{18}$ Nonetheless, patient positioning and body habitus undoubtedly can play a role in this problem, and this was most likely the case in our patient's three previous TTEs. Indeed, it has been reported that suboptimal TTE images limit interpretation in anywhere from $5 \%$ to $30 \%$ of studies, ${ }^{19,20}$ and obesity and pulmonary pathologies are very common culprits. ${ }^{21,22}$ As a consequence, the use of microbubble contrast agents has grown over the past decade as a way to better assess wall motion and chamber dimensions, ${ }^{23-28}$ but also as a way to improve the Doppler signal strength for gradient measurements. ${ }^{29}$ In our patient, the Doppler signal was only obtained with the aid of contrast enhancement (Fig. 2). As this case demonstrates, microbubble contrast-enhanced TTE can have a very important role in clinical diagnosis.

A recent large prospective study has shown that with contrast agents, "technically difficult" studies can be reduced from $86.7 \%$ to $9.8 \%$, and "uninterpretable" TTEs can decrease from $11.7 \%$ to $0.3 \%{ }^{26}$ These findings confirmed older studies that demonstrated that sub-optimal TTEs can be converted to diagnostic studies in $75 \%-90 \%$ of cases. ${ }^{22-25,27,28}$ When faced with "technically limited" TTEs, consideration should be given to either discarding the data, or ordering a study with contrast enhancement, as was done in our patient's case. Even with these technical limitations, however, TTE evaluation is non-diagnostic in less than $1 \%$ of cases, ${ }^{30}$ and the American Heart Association gives a level IIIa recommendation against the use of routine cardiac catheterization for hemodynamic measurements when evaluating aortic stenosis. ${ }^{2}$ When there is a discrepancy between sonographic data and a clinical situation, cardiac catheterization or transesophageal echocardiography (TEE) are appropriate studies for further assessment. ${ }^{2}$

There is a clear correlation between BNP levels and severity of aortic stenosis. ${ }^{31}$ Additionally, BNP levels are associated with degree of patient symptoms. ${ }^{32}$ Unfortunately, it is also well established that obesity significantly influences serum BNP levels in patients with and without heart failure. ${ }^{33-35}$ Though the molecular mechanisms for this phenomenon are not completely understood, Rappelli and colleagues have shown that natriuretic peptide receptor (NPr) gene expression is maximally expressed in adipose tissues, suggesting that increased consumption of BNP in obese individuals might explain the lower baseline levels. ${ }^{36,37}$ In light of this observation, many cardiologists have suggested utilizing a stricter cut-off value $(<50 \mathrm{pg} / \mathrm{ml})$ in ruling out heart failure in obese patients. ${ }^{33,38,39}$

This case presents a common yet extremely challenging clinical situation, where traditional diagnostic tools were impaired by a patient's obesity: borderline normal, but "technically difficult," TTEs, misinterpreted pulmonary function tests due to inadequate testing techniques, and a reassuring BNP level. In hindsight, there were numerous subtle clues that ultimately yielded the correct diagnosis despite her obesity and spurious data. Her recent history of intolerance to dialysis coupled with dyspnea and wheezing were early clues. So was the fact that she had no prior history of asthma, and that she experienced a poor response to appropriate treatment for that 
condition. Given the limitations their size imposes on traditional diagnostic workups, obese patients demand a superior knowledge of disease course and a heightened clinical awareness and flexibility. Further research is needed to help elucidate better diagnostic approaches and tools to accommodate the growing obese population in this country.

\section{KEY POINTS}

- Aortic stenosis can usually be diagnosed by a good history, physical examination, and TTE (without the use of routine cardiac catheterization).

- Obesity can be a major barrier to diagnosing aortic stenosis, and diagnostic studies including physical examination, TTE, and BNP often provide spurious data in obese patients.

- Obesity significantly impacts serum BNP levels in patients with and without heart failure.

- The diagnostic capability of TTEs in obese patients is significantly improved by the use of microbubble contrast enhancement.

\section{Acknowledgments:}

Contributors: Laura Townsend provided editorial assistance with this paper.

\section{Funders: None}

Conflict of Interest: The authors declare that they do not have a conflict of interest.

Corresponding Author: Asher A. Tulsky, MD; Division of General Internal Medicine, University of Pittsburgh Medical Center, UPMC Montefiore, 200 Lothrop Street, Pittsburgh, PA 15213, USA (e-mail: tulskyaa@upmc.edu).

\section{REFERENCES}

1. Ross J Jr, Braunwald E. Aortic stenosis. Circulation. 1968;38(1 Suppl):61-7.

2. Bonow RO, Carabello BA, Chatterjee $\mathrm{K}$, de Leon AC Jr, Faxon DP, Freed MD, et al. Focused update incorporated into the ACC/AHA 2006 guidelines for the management of patients with valvular heart disease: a report of the American College of Cardiology/American Heart Association Task Force on Practice Guidelines (Writing Committee to Revise the 1998 Guidelines for the Management of Patients With Valvular Heart Disease): endorsed by the Society of Cardiovascular Anesthesiologists, Society for Cardiovascular Angiography and Interventions, and Society of Thoracic Surgeons. Circulation. 2008;118(15):e523-661. doi:10.1161/CIRCULATIONAHA.108.190748.

3. Bonow RO, Cheitlin MD, Crawford MH, Douglas PS. Task Force 3: valvular heart disease. J Am Coll Cardiol. 2005;45(8):1334-40. doi:10.1016/j.jacc.2005.02.010.

4. Mittnacht AJ, Fanshawe M, Konstadt S. Anesthetic considerations in the patient with valvular heart disease undergoing noncardiac surgery. Semin Cardiothorac Vasc Anesth. 2008;12(1):33-59. doi:10.1177/ 1089253208316442

5. Etchells E, Bell C, Robb K. Does this patient have an abnormal systolic murmur? JAMA. 1997;277(7):564-71.

6. Etchells E, Glenns V, Shadowitz S, Bell C, Siu S. A bedside clinical prediction rule for detecting moderate or severe aortic stenosis. J Gen Intern Med. 1998;13(10):699-704
7. Kuperstein R, Feinberg MS, Eldar M, Schwammenthal E. Physical determinants of systolic murmur intensity in aortic stenosis. Am J Cardiol. 2005;95(6):774-6. doi:10.1016/j.amjcard.2004.11.035.

8. Silk AW, McTigue KM. Reexamining the physical examination for obese patients. JAMA. 2011;305(2):193-4. doi:10.1001/jama.2010.1950.

9. Weinberger M, Abu-Hasan M. Pseudo-asthma: when cough, wheezing, and dyspnea are not asthma. Pediatrics. 2007;120(4):855-64. doi: 10.1542/peds.2007-0078.

10. Rodrigo GJ, Rodrigo C, Hall JB. Acute asthma in adults: a review. Chest. 2004;125(3):1081-102.

11. Pratter MR, Hingston DM, Irwin RS. Diagnosis of bronchial asthma by clinical evaluation. An unreliable method. Chest. 1983;84(1):42-7.

12. Cabanes LR, Weber SN, Matran R, Regnard J, Richard MO, Degeorges ME, et al. Bronchial hyperresponsiveness to methacholine in patients with impaired left ventricular function. N Engl J Med. 1989;320 (20):1317-22. doi:10.1056/NEJM198905183202005.

13. Sasaki F, Ishizaki T, Mifune J, Fujimura M, Nishioka S, Miyabo S. Bronchial hyperresponsiveness in patients with chronic congestive heart failure. Chest. 1990;97(3):534-8.

14. Jorge S, Becquemin MH, Delerme S, Bennaceur M, Isnard R, Achkar $\mathbf{R}$, et al. Cardiac asthma in elderly patients: incidence, clinical presentation and outcome. BMC Cardiovasc Disord. 2007;7:16. doi:10.1186/ 1471-2261-7-16.

15. Miller MR, Hankinson J, Brusasco V, Burgos F, Casaburi R, Coates A, et al. Standardisation of spirometry. Eur Respir $J$ Off $J$ Eur Soc Clin Respir Physiol.2005;26(2):319-38. doi:10.1183/ 09031936.05.00034805.

16. Expert Panel Report 3 (EPR-3): Guidelines for the Diagnosis and Management of Asthma-Summary Report 2007. The Journal of allergy and clinical immunology. 2007;120(5 Suppl):S94-138. doi:10.1016/ j.jaci.2007.09.043

17. Otto CM, Pearlman AS. Valvular stenosis: diagnosis, quantitation, and clinical approach. In: Otto CM, Pearlman AS, eds. Textbook of Clinical Echocardiography. Philadelphia: WB Saunders Co; 1995:209-42.

18. Baumgartner H, Hung J, Bermejo J, Chambers JB, Evangelista A, Griffin BP, et al. Echocardiographic assessment of valve stenosis: EAE/ ASE recommendations for clinical practice. J Amer Soc Echocardiogr Off Publ Amer Soc Echocardiogr. 2009;22(1):1-23. doi:10.1016/ j.echo.2008.11.029. quiz 101-2.

19. Marwick TH, Nemec JJ, Pashkow FJ, Stewart WJ, Salcedo EE. Accuracy and limitations of exercise echocardiography in a routine clinical setting. J Am Coll Cardiol. 1992;19(1):74-81.

20. Senior R, Dwivedi G, Hayat S, Lim TK. Clinical benefits of contrastenhanced echocardiography during rest and stress examinations. Eur J Echocardiogr J Work Group Echocardiogr Eur Soc Cardiol. 2005;6 (Suppl 2):S6-13.

21. Mulvagh SL, DeMaria AN, Feinstein SB, Burns PN, Kaul S, Miller JG, et al. Contrast echocardiography: current and future applications. J Amer Soc Echocardiogr Off Publ Amer Soc Echocardiogr. 2000;13(4):331-42.

22. Mulvagh SL, Rakowski H, Vannan MA, Abdelmoneim SS, Becher H, Bierig SM, et al. American Society of Echocardiography Consensus Statement on the Clinical Applications of Ultrasonic Contrast Agents in Echocardiography. J Amer Soc Echocardiogr Off Publ Amer Soc Echocardiogr. 2008;21(11):1179-201. doi:10.1016/j.echo.2008.09.009. quiz 281.

23. Allen MR, Pellikka PA, Villarraga HR, Klarich KW, Foley DA, Mulvagh SL, et al. Harmonic imaging: echocardiographic enhanced contrast intensity and duration. Int J Card Imaging. 1999;15(3):215-20.

24. Cohen JL, Cheirif J, Segar DS, Gillam LD, Gottdiener JS, Hausnerova E, et al. Improved left ventricular endocardial border delineation and opacification with OPTISON (FS069), a new echocardiographic contrast agent. Results of a phase III Multicenter Trial. J Am Coll Cardiol. 1998;32(3):746-52.

25. Crouse LJ, Cheirif J, Hanly DE, Kisslo JA, Labovitz AJ, Raichlen JS, et al. Opacification and border delineation improvement in patients with suboptimal endocardial border definition in routine echocardiography: results of the Phase III Albunex Multicenter Trial. J Am Coll Cardiol. 1993;22(5): 1494-500.

26. Kurt M, Shaikh KA, Peterson L, Kurrelmeyer KM, Shah G, Nagueh SF, et al. Impact of contrast echocardiography on evaluation of ventricular function and clinical management in a large prospective cohort. J Am Coll Cardiol. 2009;53(9):802-10. doi:10.1016/ j.jacc.2009.01.005.

27. Lindner JR, Dent JM, Moos SP, Jayaweera AR, Kaul S. Enhancement of left ventricular cavity opacification by harmonic imaging after venous injection of Albunex. Am J Cardiol. 1997;79(12):1657-62. 
28. Kitzman DW, Goldman ME, Gillam LD, Cohen JL, Aurigemma GP, Gottdiener JS. Efficacy and safety of the novel ultrasound contrast agent perflutren (definity) in patients with suboptimal baseline left ventricular echocardiographic images. Am J Cardiol. 2000;86(6):669-74.

29. Nakatani S, Imanishi T, Terasawa A, Beppu S, Nagata S, Miyatake K. Clinical application of transpulmonary contrast-enhanced Doppler technique in the assessment of severity of aortic stenosis. J Am Coll Cardiol. 1992;20(4):973-8.

30. Otto CM. Valvular aortic stenosis: disease severity and timing of intervention. $J$ Am Coll Cardiol. 2006;47(11):2141-51. doi:10.1016/j.jacc.2006.03.002.

31. Gerber IL, Stewart RA, Legget ME, West TM, French RL, Sutton TM, et al. Increased plasma natriuretic peptide levels reflect symptom onset in aortic stenosis. Circulation. 2003;107(14):1884-90. doi:10.1161/ 01.CIR.0000060533.79248.0C.

32. Lim P, Monin JL, Monchi M, Garot J, Pasquet A, Hittinger L, et al. Predictors of outcome in patients with severe aortic stenosis and normal left ventricular function: role of B-type natriuretic peptide. Eur Heart J. 2004;25(22):2048-53. doi:10.1016/j.ehj.2004.09.033.

33. Maisel A, Mueller C, Adams K Jr, Anker SD, Aspromonte N, Cleland JG, et al. State of the art: using natriuretic peptide levels in clinical practice. Eur J Heart Fail. 2008;10(9):824-39. doi:10.1016/j.ejheart.2008.07.014.
34. Mehra MR, Uber PA, Park MH, Scott RL, Ventura HO, Harris BC, et al. Obesity and suppressed B-type natriuretic peptide levels in heart failure. J Am Coll Cardiol. 2004;43(9):1590-5. doi:10.1016/ j.jacc.2003.10.066

35. Wang TJ, Larson MG, Levy D, Benjamin EJ, Leip EP, Wilson PW, et al. Impact of obesity on plasma natriuretic peptide levels. Circulation. 2004;109(5):594-600. doi:10.1161/01.CIR.0000112582.16683.EA.

36. Sarzani R, Dessi-Fulgheri P, Paci VM, Espinosa E, Rappelli A. Expression of natriuretic peptide receptors in human adipose and other tissues. J Endocrinol Invest. 1996;19(9):581-5.

37. Dessi-Fulgheri P, Sarzani R, Rappelli A. The natriuretic peptide system in obesity-related hypertension: new pathophysiological aspects. J Nephrol. 1998;11(6):296-9.

38. Horwich TB, Hamilton MA, Fonarow GC. B-type natriuretic peptide levels in obese patients with advanced heart failure. J Am Coll Cardiol. 2006;47(1):85-90. doi:10.1016/j.jacc.2005.08.050.

39. Bayes-Genis A, Lloyd-Jones DM, van Kimmenade RR, Lainchbury JG, Richards AM, Ordonez-Llanos J, et al. Effect of body mass index on diagnostic and prognostic usefulness of amino-terminal pro-brain natriuretic peptide in patients with acute dyspnea. Arch Intern Med. 2007;167 (4):400-7. doi:10.1001/archinte.167.4.400. 